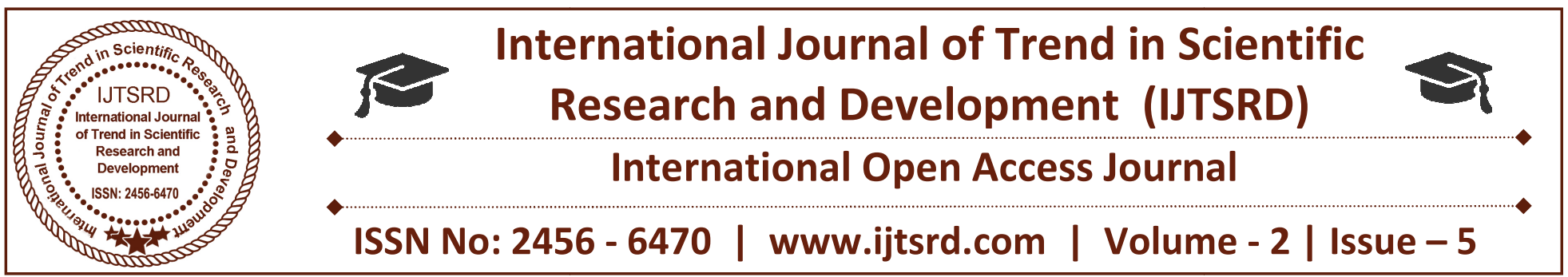

\title{
Comparison of Different Liquids Used in Fuel System of an Aircraft
}

\author{
J. Nirmala ${ }^{1}$, S. Indumathi ${ }^{2}$ \\ ${ }^{1}$ Assistant Professor, ${ }^{1}$ Research Scholar \\ KG College of Arts and Science, Coimbatore, Tamil Nadu, India
}

\begin{abstract}
There have been several aircraft accidents, due to the water/ice formation in the aviation fuel. It concern a computational study of the process of removing water from an aircraft fuel tank by pumping Nitrogen Enriched Air from the bottom of the tank. This is important procedure for smooth, efficient, and safe operation of the aircraft engine. Since the large transport airplanes fly at very high altitudes, where ambient temperature can reach $-6 \mathrm{c}$, water may freeze can blockage in fuel tank. In order to reduce the water contamination in fuel tank by pumping NEA through fuel tank as a part of their inerting. finally, it conclude the amount of accumulated water is depend on the bubble size and rising speed velocity can be calculated.
\end{abstract}

KEYWORD: Aircraft, water contamination, fuel system, On Board Inert Gas Generation System, Nitrogen Enriched Air, Bubble

\section{INTRODUCTION}

Fire and explosion of fuel tank is one of the major reason for the aircraft accident, due to the water / ice formation within the fuel tank system. Since the large transport airplanes fly at very high altitudes, where the ambient temperature can reach at $-6^{\circ} \mathrm{c}$, water may freeze causing blockage in the fuel lines, leads to engine thrust reduction or engine shut down. The aim of this paper to increase flignt safety by minimizing the effect of water/ice formation in the aviation fuel. In the proposed methodology, water contamination is eliminated by extracting water from the fuel by using water/fuel separator. The On Board Inert Gas Generation System (OBIGGS), which is already installed on some aircraft to prevent the outbreak of fire in the fuel tank, is a potentially feasible method to improve the water management.
In order to explore the bubble effect, the relationship between the orifice configuration and bubble parameter, bubble model, the effect of bubble size and rising speed velocity can be calculated by means of mathematical calculation.

\section{AIRCRAFT}

Aircraft is a machine that is able to fly by gaining support from the air. It counters the force of gravity by using either static lift or by using the dynamic lift of an airfoil. commom examples: airplanes, helicopters, airships, hot air balloons.

\section{AVIATION FUEL}

Aviation fuel is a special type of petroleum based fuel used to power aircraft. It ig generally high guality of fuels used in less critical applications, such as heating or road transport, often it contain additives to reduce the risk of icing or explosion due to high temperature, among other properties.

\section{JET FUEL}

Jet fuel is a clear to straw colored fuel based on either an unleaked kerosene, or a naptha - kerosene blend. Similar to disel fuel, it can be used in either compression ignition engines or turbine engines

\section{AMBIENT TEMPERATURE}

Ambient temperature is the air temperature of an environment of an environment or object. In conputing, ambient temperatures refer to the air surrounding computing equipment.

\section{ORIFICE}

An orifice is a small opening provided on the side or bottom of a tank, through which a fluid is flowing. The opening can be of any shape or cross - section, 
like rectangular, triangular, or circular. The orifices may discharges fluid into the atmosphere or from one tank to another.

\section{FROUDE NUMBER (Fr)}

It is the ratio of inertial and gravitational forces. It is utilized to analyse fluid flow problems where there is a free surface.

$$
\mathrm{Fr}=\frac{v}{\sqrt{g D}}
$$

Where $\mathrm{V}$ is the velocity of water

$\mathrm{g}$ is the acceleration due to gravit

$\mathrm{D}$ is the hydraulic depth

\begin{tabular}{|c|c|}
\hline $\begin{array}{l}\text { Froude } \\
\text { number }\end{array}$ & Flow type \\
\hline $\mathrm{Fr}=1$ & Flow is critical if is equal to 1 \\
\hline $\mathrm{Fr} \succ 1$ & $\begin{array}{c}\text { Greater than } 1 \text { means flow is } \\
\text { supercritical }\end{array}$ \\
\hline $\mathrm{Fr} \prec 1$ & $\begin{array}{l}\text { If it less than } 1 \text { means subcritical } \\
\text { flow will occur }\end{array}$ \\
\hline
\end{tabular}

\section{EOTOVOS NUMBER OR BOND NUMBER}

\section{$\left(\mathbf{B d}_{0}\right)$}

Eotovos number (Eo) is also called as Bond number (Bo), ia a dimensionless number measuring the importance of gravitational forces compared to surface tension forces and is used together with morton number to characterize the shape of bubbles or drops moving in a surrounding fluid.

$$
E_{o}=B_{o}=\frac{\Delta \rho g L^{2}}{\sigma}
$$

Difference in density of two phases

$\mathrm{G}$ is the gravitational acceleration

$\mathrm{L}$ is the characteristic length

$\sigma$ is the surface tension

\section{ACCIDENT DUE TO FUEL TANK}

It is very difficult for a pilot to determine if there is a leak in the fuel tanks. For example, china airlines B737-800 destroyed by fire at naha airport in japan on august 20 2007, due to water/ice formation that causes leakage in the fuel tank. Another example, British Airway Boeing 777-236 departed London Heathrow enroute to Harare in Zimbabwe on 10 june 2004. Immediately after takeoff, a fuel leak was detected and emergency landing initiated. The UK Air Accident Investigation Branch (AAIB) revealed that he fuel leak due to the water contamination in the fuel tank. The fuel escaping through the centre fuel tank purge door inside the left main landing gear.

\section{WATER CONTAMINATION IN AIRCRAFT FUEL TANK}

Water is accumulated in the aircraft fuel tanks, during flight due to the condensation as the moist air enters the tank through the fuel vent ports. water contamination can occur during normal aircraft operation, when aircraft is flying at very high altitude .At high altitude the ambient temperature can reach -6 ${ }^{o} \mathrm{c}$, in such temperature both the fuel and wing tank structure become extremely cold and as air enters the fuel tank for ventilation, espically in tropical climates, the air is very humid and it hits the fuel tank structure, it condenses as result water droplets will form. The large quantity of outside air entres the fuel tank due to pressure differences between the outside and fuel tank .Therefore during descent, large amount of air enters fuel tank and as the humid air condenses on the cold fuel tank structure, water is formed. Water mixes with the fuel inside fuel tank. Kerosene also absorbs water from atmosphere. Water can enter aircraft fuel tanks via fuel vent ports during; aircraft washing process if the vent ports are not sealed; aircraft parked at the terminal in a rainy/snowy weather condition, and as aircraft flies through the clouds and thunderstorms, moist enters the tanks through fuel vent ports. Water can enter an aircraft fuel system through leaks in the fuel vents, deteriorated seals, or poorly fitted fuel caps, refueling aircraft during rain or snowstorms, during aircraft wash, by condensation and precipitation, especially if the aircraft fuel tanks are partially filled with fuel. Fuel contamination can result in loss of all propulsive power since the problem affects all engines; perhaps the most common source of fuel contamination is water... water in fuel can be undetectable at concentration level of $80 \mathrm{PPM}$ at ground ambient conditions. The water in the fuel can take one of the three forms: dissolved, entrained (suspended) and free water. Dissolved water occurs when a water molecule attaches to a hydrocarbon molecule that the amount dissolved water in fuel depends on humidity, temperature and chemical constitution of the fuel. Dissolved water is not a problem for aircraft operation, it cannot be removed by filtration, however, if fuel temperature reduces to below zero degrees, it will cause dissolved water to come out of solution as free water which can cause operating problems. Entrained water in fuel, when freezes, it forms ice crystals, and since the density of ice crystals is approximately the same as 
the fuel, the ice crystal stays in suspension and drift within fuel. Ice crystals form around $-1^{\circ} \mathrm{C}$ to $-3^{\circ} \mathrm{C}$, and as temperature of water is further reduced to 'Critical Icing Temperature' that is between $-9^{\circ} \mathrm{C}$ and $-11^{\circ} \mathrm{C}$, the ice crystal start to stick to the surroundings. As temperature of water is further reduced to $-18^{\circ} \mathrm{C}$, the ice crystals start to adhere to each other and they become large, with risk of blocking small orifices. Free water is neither dissolved nor entrained and since they have higher density of fuel, it takes form of droplets or puddles of water lying on the bottom of tank. As free water cool below its freezing point, they form ice.

\section{EFFECT OF WATER CONTAMINATION IN AVIATION FUEL}

Water can cause rust and corrosion of iron components thus it forms loose particles of iron oxide, which the fuel nozzle wear and subsequently its failure over a period.water in fuel at very high altitude freezes and can block the fuel pipeline thus stop or severely restrict the fuel flow to the engine. the engine flame out, or even engine shut down. Fuel contamination in the result of loss of all propulsive power and it effect the engine .water in the fuel is undetectable at the concentration level of 80 PPM at the ground ambient level.

In 1982, ice formation in the aviation fuel it causes crash of an Air Florida Boeing 737 at Washing National Airport. The fuel in the wing comes in very close proximity to the aircraft skin, and become very cold, especially in cold weather conditions or high altitudes. Thus, the cold fuel acts like a refrigerator, which it cools the outside air and cause frost or ice to form on the wings, therefore the ice can form on the wings when there is no visible moisture. The two types of fuel heaters commonly used on large transport airplanes. Fuel heaters introduced on large transport airplanes to minimize the effect of fuel icing. These heaters usually use hot engine bleed air or hot engine oil, to heat fuel through a heat exchanger. The heat exchanger using bleed air is located on the spar or in engine pylon area, and the heat exchanger using hot engine oil is located on the engine, and the heat exchanger. However, most of water in fuel tanks take the form of free water and entrained water, which gradually settle on the bottom of the fuel tank. This condition presents the most risks, because, when water temperature reduces to below $0^{\circ} \mathrm{C}$, it freezes, and it can block the scavenge jet pumps and block the inlet screen of fuel booster pumps. In addition, result in fuel flow restriction to the engine. Fuel system icing inhibitor is a fuel additive used on some business jets; however, it is not commonly used in large public transport aircraft. It is only effective on undissolved water.

\section{FUEL TANK AND ON BOARD INERT GAS GENERATION SYSTEM (OBIGGS) MODEL}

The purpose of OBIGGS was to avoid the mixture of flammable fuel and air which could ignite in the tank. In terms of water contamination, the water is generated by two sources: precipitation of dissolved water and condensation of moist air. The OBIGGS can reduce humidity in the tank and warm the ullage or fuel to prevent water contamination. Therefore, OBIGGS could save the time and the cost of maintanence by stoping the water contamination in the aviation fuel.

The major causes of water contamination are

$>$ Inflow/ outflow through the vent system

$>$ NEA gas injection, absorption of dissolved water Water condensation on the wall

Water precipitation in the fuel

The Nitrogen Enriched Air gas is injected through the vent. It absorb the dissolved water in fuel tank. The effect of the NEA bubbles on the water absorption.

Bubble diameter can be expressed in three dimensionless number that is Froude number (fr), bond number $\left(\mathrm{Bd}_{o}\right)$, Galileo number $(\mathrm{Ga})$.

The equation can be expressed in the form of

$$
\frac{d_{m}}{d_{0}}=26\left(\frac{d_{0}{ }^{2} g \rho_{L}}{\sigma}\right)^{-0.5}\left(\frac{d_{0}{ }^{3} g}{v^{2}}\right)^{-0.12}\left(\frac{U_{T}}{\sqrt{g d_{0}}}\right)^{-0.12}
$$

The bubble diameter with various surface tension or liquid viscosities.

$$
\frac{d_{m}}{d_{0}}=\left[\frac{5.0}{B d_{0}{ }^{1.08}}+\frac{9.261 F r^{0.36}}{G a^{0.39}}+2.147 F r^{0.51}\right]^{\frac{1}{3}}
$$

Where $\mathrm{Bd}_{0}$, Fr, Ga represent the Bond Number, Froude Number, and Galileo Number.

$$
\begin{gathered}
\mathrm{Bd}_{0}=\frac{d_{0} g \rho_{L}}{\sigma} \\
\mathrm{Fr}=\frac{U_{s o}{ }^{2}}{g d_{0}}
\end{gathered}
$$


International Journal of Trend in Scientific Research and Development (IJTSRD) ISSN: 2456-6470

$$
\mathrm{Ga}=\frac{d_{0}^{3} g}{v^{2}}
$$

Where is the initial speed at the injection nozzle it can be divided by the injection gas flow $\mathrm{Q}$ by the orifice area $\Pi r_{0}{ }^{2}$.

$$
U S O=\frac{V_{N E A}}{N_{\text {orifice }} \cdot \pi\left(\frac{d_{0}}{2}\right)^{2}}
$$

\section{PROPERTIES OF LIQUIDS}

The different viscosity and density of fuel like methanol, ethanol and propanol in the aviation fuel. The methanol has less attension when compared to the ethanol and propanol fuel. so propanol and ethanol content are mostly used in the aviation fuel. The methanol is mostly used in the racing cars.

The ethanol and propanol viscosity with different temperature are tabulated below

\section{Properties of liquids}

\begin{tabular}{|c|c|c|}
\hline Temperature & $\begin{array}{c}\text { Viscosity } \\
\text { of water }\end{array}$ & $\begin{array}{c}\text { Viscosity } \\
\text { of ethanol }\end{array}$ \\
\hline $20^{\circ} \mathrm{c}$ & 0.0012 & 0.0014 \\
\hline $40^{\circ} \mathrm{c}$ & 0.0065 & 0.00018 \\
\hline $60^{\circ} \mathrm{c}$ & 0.0046 & 0.0015 \\
\hline
\end{tabular}

Graph shows the viscosity of water decreases where the ethanol content in the aviation fuel is more. The ethanol viscosity in increasing at different temperatures.

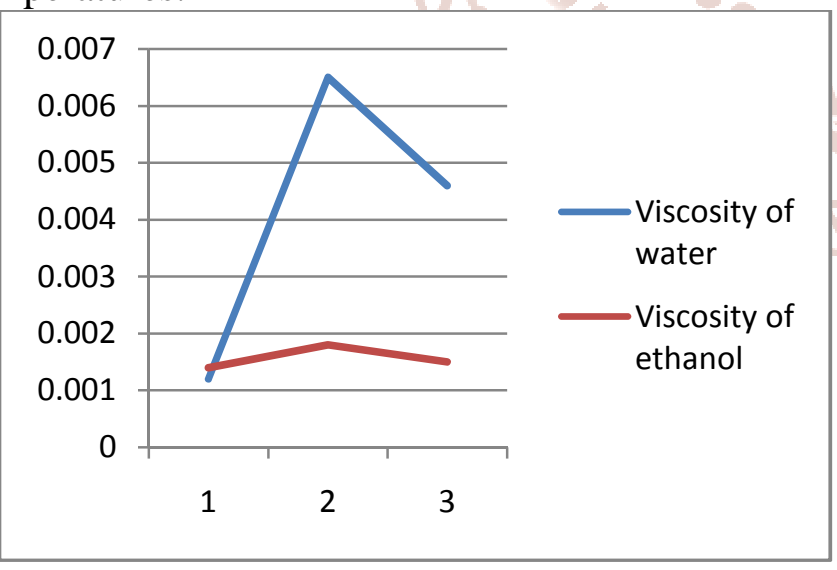

\begin{tabular}{|c|c|c|}
\hline \multicolumn{3}{|c}{ Properties of liquid } \\
\hline $20^{\circ} \mathrm{c}$ & 0.0012 & 0.0018 \\
\hline $40^{\circ} \mathrm{c}$ & 0.0065 & 0.023 \\
\hline $60^{\circ} \mathrm{c}$ & 0.0046 & 0.0421 \\
\hline
\end{tabular}

The viscosity of water is increasing where the effect of viscosity of propanol in the fuel system. The viscosity of water is less when compared to propanol with different temperatures.

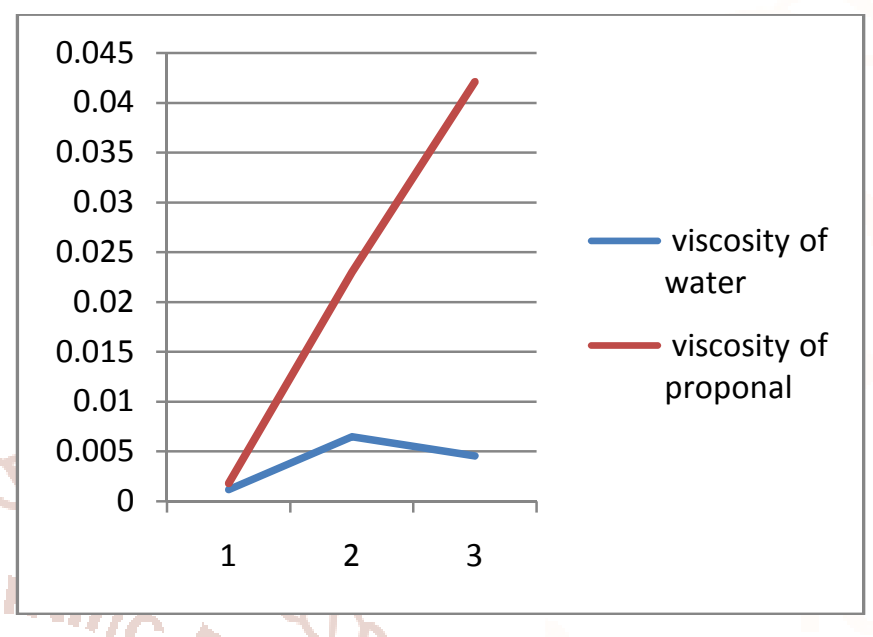

\section{CONCLUSION}

The properties of ethanol, propanol and methanol can be analysed and compared the liquids which are in the aviation fuel. The different liquids content in the aviation fuel is ethanol and proponal. The viscosity of propanol is more than the viscosity of ethanol. So water can be easily drained in the propanol liquid as well as the ethanol fuel in the aviation fuel. Because it has varies viscosity at different temperatures. The methanol fuel has less attention than ethanol and propanol as an alternative to petroleum based fuel. It is mostly used in racing cars in many countries. In aircraft system mosty propanol based content fuel is used in the aviation fuel and jet fuel.

\section{REFERENCES}

1. Boeing (2015) Boeing 777 Aircraft Maintenance Manual Chapter, USA.

2. Mehta K. Water and ice management in fuel systems using OBIGGS. MSc Thesis, Cranfield University, UK, 2013

3. Kulkarni AA and Joshi JB. Bubble formation and bubble rise velocity in gas-liquid systems. Ind.Chem eng.2005; 44: 5873-5931

4. Jamialahmadi, M. and Mu“ller-Steinhagen, H., 1992, Effect of alcohol, organic acid and potassium chloride concentration on bubble size, bubble rise velocity and gas holdup in bubble columns.

5. Gaddis, E. S. and Vogelpohl, A., 1986, Bubble formation in quiescent liquids under constant Low conditions, Chem Eng Sci, 41, 97-105. 